\title{
Application and Analysis for Surge Arrester on Lightning Protection of Distribution Network
}

\author{
Daxing WANG ${ }^{1, a}$, Bin $\mathrm{HE}^{1}{ }^{1}$,Wei ZHONG ${ }^{1}$, Bo LIN ${ }^{1}$, Dong WANG ${ }^{1}$, Tingbin $\mathrm{LI}^{1}$ \\ ${ }^{1}$ SICHUAN TONG YUAN ELECTRIC POWER SCIENCE\&TECHNOLOGY CO., LTD, Chengdu,China
}

\begin{abstract}
In order to effectively reduce lightning stroke outage rate, effect of lightning protection with surge arrester on transmission line has been generally acknowledged relative to other lightning protection measures. This article introduces in such aspects as the working principle of line surge arrester and effect of lightning protection, and also explores application for lightning arrester of distribution network to achieve difference lightning protection and improve the lightning protection performance of distribution network.
\end{abstract}

\section{Introduction}

According to operational experience at home and abroad, lightning stroke is the main reason to cause line tripping and service interruption, according to the statistical report of interruption of service in china, $40 \% \sim 70 \%$ of the accident in the power system are caused by lightning which has brought a great loss to national economy.

In general, the methods which include improving the insulation level of line, decreasing grounding resistance, decreasing protection angle and so on have been used in cutting down lightning accidents. However, the way of improving the insulation level of line would markedly increase line costs, also, it is extremely difficult for decreasing grounding resistance in the area with high soil resistivity. At the same time, the way of decreasing protection angle would be limited by the structure of towers. Operational experience has shown that there is still not very good response to significantly reduce lightning accidents for transmission lines located in complex terrain and high soil resistivity areas.

Therefore, some countries have made zinc oxide surge arresters install on transmission lines for reducing lightning accident measures since 1980. In the United States and Japan, the surge arresters had successfully applied on transmission lines.

As technology advances, china have also developed $10 \sim 500 \mathrm{kV}$ line surge arresters, and has been used extensively for lightning protection of transmission and distribution lines. Operational experience has proved that surge arrester which used in strong lightning activity or high soil resistivity areas can effectively improve lines lightning withstand level.

\section{The working principle of surge arrester}

\footnotetext{
a Corresponding author: wangdxsepri@163.com
}

Surge arrester generally uses the body and air gap, and surge arrester does not assume system operating voltage, without considering the long-running voltage electrical aging, also the body failure does not affect operation.

when a lightning flash directly strikes the tower, part of the lightning current flows through the grounding wire to adjacent tower, the other part of the lightning flows into the earth through the tower, grounding resistance of tower manifested transient resistance characteristic, it is generally characterized by the impulse grounding resistance. The electric potential of cross arm rapidly increases when lightning strikes the tower, its potential value is

$$
V_{t}=i R_{i}+L \frac{d i}{d t}
$$

In the equation.

i- lightning current.

$\mathrm{Ri}$ - impulse grounding resistance.

$L \frac{d i}{d t}$ - transient state component.

When the potential difference of cross arm potential $(\mathrm{Vt})$ and line induced potential (V1) is more than 50\% discharge voltage of the insulator string(U50\%), the equation is $V_{t}-V_{I} \succ U_{50 \%}$, flashover will take place from cross arm to line. If we consider the amplitude of power frequency voltage (Um), it will be $V_{t}-V_{I}+U_{m} \succ U_{50 \%}$.

Therefore, lightning withstand level associates with four important factors, such as 50\% discharge voltage of the insulator string, lightning current, overhead ground wire and impulse grounding resistance of the tower.

Lightning current associated with location and atmospheric conditions, reducing grounding resistance of tower is main measures for improve lightning withstand 
level of transmission lines without the use of surge arresters. Especially, it is very difficult to reduce grounding resistance in the mountains, which led to line tripping frequently struck by lightning.

After the installation of surge arresters, surge arrester is parallel with insulator. When transmission line being struck by lightning, part of the lightning current flows through the grounding wire to adjacent tower, the other part of the lightning current flows into the earth through the tower. when lightning current exceeds the action value of the arrester, current will flow through the arrester.

After lightning current pouring, continuous frequency current flowing through the surge arrester is only $\mathrm{mA}$ level, the arrester will cut off continuous frequency current in the first zero crossing of current, so dielectric strength fast recover. Therefore, surge arrester have a good holding potential role to ensure insulator string flashover not to occur, thus achieve the goal which prevent transmission line lightning trip.

\section{Analysis of lightning withstand level of $35 \mathrm{kV}$ lines}

$35 \mathrm{kV}$ line belong to medium voltage network, it is one of China's major power distribution network. Distribution network has low insulation level and a complex network structure, also there is no grounding wire, coupling ground, surge arresters and other protective measures. So that, line tripping and service interruption of distribution network will be easily caused by direct lightning or induction lightning in the weather of thunderstorms .

Lightning withstand level of transmission lines is a important indicators to measure effect of lightning protection, it concerns with the size of tower, impulse grounding resistance, number of insulator, the type of insulator, terrain around the tower, operation and maintenance level and so on.

Based on the investigation of a power company, its $35 \mathrm{kV}$ line insulators configured to $3 \mathrm{WP}-7$ type insulators, line insulation level is low, direct lightning or induction lightning all easily lead line trip.

The main words in all headings (even run-in headings) begin with a capital letter. Articles, conjunctions and prepositions are the only words which should begin with a lower case letter.

These guidelines, written in the style of a submission to MATEC Web of Conferences, explain how to prepare your paper using Microsoft Word.

Please submit sources files directly to the conference organizer. If the conference editors chose to provide print-ready PDF documents to the publisher, you have to submit high-resolution PDF file with all fonts embedded (see PDF guidelines) instead of the sources files. In this case, please remember that no final corrections will be made by the publisher.

\subsection{Direct lightning stroke}

When transmission line being struck by lightning, lightning current flows through the wire to both sides of the shunt, as shown in Figure 1. Before the reflected wave formation, the ratio of voltage and current of line is impedance $Z$. Impedance of overhead lines in the atmosphere over-voltage is nearly equal to $400 \Omega$. Lightning current flows along the road on both sides, that is $i_{S} / 2$, the equivalent circuit shown in Figure 1 , over voltage of direct lightning on the overhead line $\mathrm{Ug}$ is

$$
U_{g}=\frac{i_{S}}{2} \times \frac{Z}{2}=100 I
$$
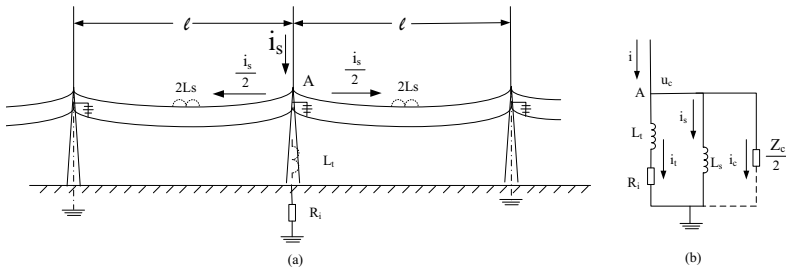

Fig. 1 Note Top of the tower struck by lightning and equivalent circuit diagram

When transmission line without ground lines being struck by lightning, lightning current I which causes the insulator string flashover is

$$
I=U_{50 \%} / 100
$$

In the equation, $\mathrm{U} 50 \%$ is $50 \%$ discharge voltage of the insulator string. Flashover voltage of three insulators is generally $117.36 \times 3=352.08 \mathrm{kV}$. Through equation $(1.3)$ lightning current which causes the insulator string flashover is $3.52 \mathrm{kA}$.

According to the lightning current amplitude accumulative probability equation (1.4)

$$
\lg P=-I / 88
$$

In the equation (1.4), I is lightning current amplitude $\mathrm{kA} ; \mathrm{P}$ is the probability that the lightning current amplitude exceeds I. Through equation (1.5) to calculate the probability $\mathrm{P}$ is $91 \%$, it means $91 \%$ of lightning would cause line tripping if line being struck by the lightning.

\subsection{Direct lightning stroke}

When transmission line being struck by lightning, lightning current flows through the wire to both sides of the shunt, as shown in Figure 1.

According to national regulation, when the thundercloud discharge to ground distance from the overhead line over 65 meters, it will generate voltage in the line. The maximum value of induced voltage can be calculated as follows:

$$
U_{g}=25 \frac{I \times H_{c}}{S}
$$

In the equation (1.5), $\mathrm{Ug}$ is the maximum voltage induced by lightning, $\mathrm{kV}$; I is lightning current amplitude (generally no more than 100), $\mathrm{kA} ; \mathrm{Hc}$ is the average height of the wire, $\mathrm{m} ; \mathrm{S}$ is the distance between lightning and the wire, $\mathrm{m}$. 
In the equation (1.5), over-voltage induced by lightning is proportional to the average height of overhead line. Induced voltage is generally not more than $300 \mathrm{kV}$, however, it is easy to occur insulator flashover due to induced voltage in $35 \mathrm{kV}$ and below distribution network.

\section{Application and effect for surge arrester on distribution network}

Distribution network of certain power company distributes in a hilly area which has frequent lightning activity. According to statistics from 2000 to $2009,35 \mathrm{kV}$ line was struck by lightning more than 100 times, in which direct damage to insulators and interior electronic equipment were about 40 times.

Through analysis of lightning disturbance among past years, combined with the line being struck by lightning frequency and geographic location characteristics, it is effective to install line surge arresters without gaps in parallel with insulator for protecting the insulator and substation equipment, also it can improve lightning withstand level of transmission lines and reduce lightning accident rate.

Table 1 Lightning trip rate before and after the installation of line surge arresters

\begin{tabular}{|c|c|c|c|c|}
\hline \multirow{2}{*}{ Line Name } & \multirow{2}{*}{$\begin{array}{l}\text { Line trip and } \\
\text { arrester cases }\end{array}$} & \multicolumn{3}{|c|}{ Year of operation } \\
\hline & & 2006 & 2007 & 2008 \\
\hline \multirow{2}{*}{$\begin{array}{l}\text { 35kV Daguan } \\
\text { line }\end{array}$} & $\begin{array}{l}\text { Annual trip } \\
\text { Frequency }\end{array}$ & 3 & 0 & 0 \\
\hline & $\begin{array}{l}\text { The number of } \\
\text { arrester operation }\end{array}$ & 18 & 44 & 46 \\
\hline \multirow{2}{*}{$\begin{array}{c}35 \mathrm{kV} \\
\text { Dongdan line }\end{array}$} & $\begin{array}{l}\text { Annual trip } \\
\text { Frequency }\end{array}$ & 5 & 1 & 0 \\
\hline & $\begin{array}{l}\text { The number of } \\
\text { arrester operation }\end{array}$ & 36 & 41 & 51 \\
\hline \multirow{2}{*}{$\begin{array}{c}35 \mathrm{kV} \\
\text { Rezhong line }\end{array}$} & $\begin{array}{l}\text { Annual trip } \\
\text { Frequency }\end{array}$ & 3 & 1 & 0 \\
\hline & $\begin{array}{l}\text { The number of } \\
\text { arrester operation }\end{array}$ & 58 & 59 & 26 \\
\hline \multirow{2}{*}{$\begin{array}{l}35 \mathrm{kV} \text { Fubei } \\
\text { line }\end{array}$} & $\begin{array}{l}\text { Annual trip } \\
\text { Frequency }\end{array}$ & 9 & 2 & 1 \\
\hline & $\begin{array}{l}\text { The number of } \\
\text { arrester operation }\end{array}$ & 70 & 132 & 64 \\
\hline
\end{tabular}

According to line lightning trip statistics from 2006 to 2008 in the power company, most of line towers that occurs lightning trip were not used as an effective lightning protection measures. According to the lines which occurs frequent lightning trip in early time, the number of lightning trip was significantly decreased after the installation of line surge arrester. Such as Fubei line before installing line surge arrester, lightning trip in 2006 is 9 times, and the number decrease to only 2 times in 2007 after the line surge arrester installed, while the number of line arrester action is 132 times; Dongdan line had the same phenomenon, which lightning trip in 2006 is 5 times, and the number decrease to only 1 time in 2007 after the line surge arrester installed, while the number of line arrester action is 41 times.

Therefore, line surge arrester effectively avoid lightning trip accidents occurring by way of installing line surge arrester after correctly choosing the tower which easily be struck by lightning, so that lightning withstand level of transmission lines has been effectively improved. Fewer number of lightning trip in Daguan line and Dongdan line after 2007 is a close relationship with installation of line surge arresters, at the same time, we should combine the characteristics of lightning activity and terrain in the region to flexibly adjust the installation location of arrester, and make the arrester applications to maximize the effect.

\section{Conclusion}

Effect of lightning protection with surge arrester on transmission line has been generally acknowledged relative to other lightning protection measures. Especially, surge arresters can significantly reduce lightning accidents for transmission lines in complex terrain and high soil resistivity area.

Distribution network develop rapidly at the present time, a large number of line put into operation each year, expanding the size of the line increases the probability of lightning trip, also brought more difficulty to lightning protection work. From the technical economy view, not all towers can be installed by surge arresters, so we should selective install arresters combined with the line being struck by lightning frequency and landform characteristics and so on.

Given the current situation in lightning protection work, proposed to continue to promote the application of line surge arrester, the effect of line arrester depends on correctly selecting the section or tower which is apt to be stroke. At the same time, a lot of arresters hanging on the towers in a certain extent increase the pressure of maintenance of the line, it should be appropriately controlled the scale.

\section{References}

1. ZHANG Zhijin, SIMA Wenxia, JIANG Xingliang. Study on The Lightning Protection Performance of Shielding Failure for UHV\&EHV Transmission Lines[J].Proceedings of the CSEE, 2005,25(10):1-6.

2. YI Hui. The Analysis of Lightning-protection Performance and the Improvement Measure for the Shared Tower Double-circuit 500kV Transmission Lines[J]. High Voltage Engineering, 1998,24(2):5255. 
3. XIAO Guobin. Research on Line Arrester Applications on Improving lightning withstand level of AC Transmission Line[J]. Insulators and Surge Arresters, 2003(9):27-29.

4. Study on Adopting $\mathrm{ZnO}$ Arrestor to Increase Lightning Withstand Level of 220kV Transmission Line[J]. High Voltage Engineering, 1998, 24(3):7779.

5. Ohkiet al. Lightning arresters developed for $500 \mathrm{kV}$ transmission lines. IEEE Electrical Insulation Magazine, 1994, 10 (4): 61.

6. CHENG Xueqi.Application of Lightning Arresters on Transmission Lines[J]. ELECTRIC POWER, 1999, 32(8): 66-67.

7. WANG Bingjun. Metal oxide surge arresters [M]. Beijing: China WaterPower Press, 1993.

8. QIU Xuehua. Application and Research on Linesurge Arrester on Transmission Line[D]. Guangdong University of Technology.2007.

9. LI Jinglu. Modern Lightning Protection Technology [M]. Beijing: China Water Power Press, 2009.

10. DL/T620-1997. Overvoltage protection and insulation coordination for $\mathrm{AC}$ electrical installations $[\mathrm{S}]$. 